Hospital School of Medicine; on Dr. H. Urich (neuropathology), in respect of his post at the London Hospital Medical College; on Dr. P. L. Williams (experimental neuroanatomy), in respect of his post at Guy's Hospital Modical School.

Oxford

IN an oration published in the annual report as a supplement to the Oxford University Gazette of October 2,1964 , the Vice-Chancellor announced that it had been possible, thanks to the initiative of Merton, All Souls, Christchurch and St. John's Colleges, to make a start with the creation of two new graduate societies for nonFellows (Supplement No. 3209. Pp. 51-77. Oxford: The University, 1964. 2s.). A capital grant of $£ 29,000$ had been promised to the University with recurrent grants for ten years to ensure an annual income of $£ 18,000$. The Vice-Chancellor expressed tho view that doors should be left open, as in the past, for those who contribute to the life of the University in other ways than as tutors or research workers. The annual report records an increase of 174 in the number of matriculated students in residence compared with 1962-63; of the 8,963 students in 1963-64, 7,558 were men. Of the total, 412 men and 60 women came from Commonwealth countries and 550 men and 80 women from other countries. Besides the establishment of two posts of University lecturer status in each of the Faculties of Physical and Biological Sciences, a new professorship was established in the Department of Engineering Science through funds made available by Messrs. Stewart and Lloyds, to cover a period of seven years in the first instance, and this professorship of structural engineering will be known as the Stewart and Lloyds professorship.

\section{Canadian Awards in Chemical Engineering}

G. C. M. MacKay and S. G. Mason (McGill University and the Pulp and Paper Institute, Montreal) have received the award of the Chemical Engineering Division of the Chemical Institute of Canada for the best paper published in The Canadian Journal of Chemical Engineering during the year, in respect of their paper entitled "The Gravity Approach and Coalescence of Fluid Droplets at Liquid Interfaces". In the Division's 1964 Student Paper Competition, J. Morgan (University of British Columbia) was awarded first place and I. Patterson (McGill University), second.

\section{IBM Scholarships}

FIVE new scholarships, together amounting to about $£ 10,000$, are to be awarded each year by IBM United Kingdom, Ltd. The scholarships will provide grants for students wishing to attend any British university. The grants will be worth about $£ 600$ per annum each, and will be available for covering a maintenance allowance and certain university feos and expenses. Such grants will be given to candidates who have obtained places at residential universities; reduced grants will be available for succossful applicants who will live at home during the term. Although there will be no obligation on either side, IBM scholars will be given preferential consideration if they wish to join the Company aftor graduation. Initial interviews will be held in February and March, and final interviews will be held during the Easter vacation. Application forms, which should be submitted through headmasters and headmistresses, and furthor details are available from the Director of Personnel, IBM United Kingdom, Ltd., 101 Wigmore Street, London, W.1.

\section{Smithsonian Observatory Post-doctoral Research Programme}

A POST-DOCTORAL fellowship programme for research associates has been established at the Smithsonian Astrophysical Observatory, Cambridge, Massachusetts. Two appointments for visiting scientists from U.S. or overseas institutions will be available in January 1965 with two additional appointments available in July. The Astrophysical Observatory is one of several Smithsonian Institution bureaux which will offer such a programme in co-operation with the U.S. National Academy of Sciences-National Research Council. Research associateships will be offered to scientists pursuing post-dcctoral investigations in the general fields of applied ar.d treo:etical space sciences, astronomy, astrophysics, and celestial mochanics. Two types of appointment will be available: regular associateships for scientists at the immediate post-doctoral level, and senior associateships for scientists who are five years past their doctorates and who are already engaged in research activities resulting in publication or recognition in their fields. Associateships are available to scientists from the United States and overseas. The stipend for the regular post-doctoral research associateships is 10,000 dollars per annum. Appointments will normally be for one year. The U.S. National Academy of Scionces-National Research Council will administer the programme. Further information and application forms can be obtained from the U.S. National Academy of Sciences-National Research Council, 2101 Constitution Avenue N.W., Washington, D.C. 20560.

\section{Announcements}

A symposium on "Human Palaeopathology", organized by the U.S. National Academy of Sciences-National Research Council, will be held in Washington on January 14. Further information can be obtained from the U.S. National Academy of Sciences-National Research Council, 2101 Constitution Avenue, Washington D.C. 20418.

THE fifth summer research institute of the Australian Mathematical Society will be held at the Australian National University, Canberra, during January 11February 19. Further information can be obtained from the secretary of the Institute, J. S. Sandiford, School of Mathematics, University of New South Wales, Kensington, New South Wales.

THE fifth seminar of "Electrochemistry" will be held at the Central Electrochemical Research Institute, Karaikudi, during January 27-30. The programme will include technical sessions on: electrode kinetics, electrochemical equilibria and electroanalysis; electro-organic and -inorganic products; electrothermics and electrometallurgy; batteries; electrodeposition and metal finishing; corrosion; miscellaneous. Further information can be obtained from Dr. M. A. V. Devanathan, Central Electrochemical Research Institute, Karaikudi 3.

Corrigendum. In the communication by Prof. J. L. R. Candela et al. entitled "Effect of Glucose on Insulin Secretion in vitro by Rabbit Pancreas pre-incubated with 3-Hydroxybutyrate" (Nature, 203, 758; 1964) lines 16 and 17 should read "... Krebs-Henseleit buffer containing $\beta$-hydroxybutyrate $1 \times 10^{-2} \mathrm{M} . .$.

CORRIGENDUM. In the article entitled "Distribution of Particle Size in Dust" (Nature, 203, 1057; 1964), equation (3) should read:

$$
p(D)=(\gamma-1) D^{-\gamma} / D_{S^{1-\gamma}}-D_{L}^{1-\gamma}
$$

Equation (4) should read:

$$
P(D)=\left(D_{S^{1-\gamma}}-D^{1-\gamma}\right) /\left(D_{S^{1-\gamma}}-D_{L^{1-\gamma}}\right)
$$

and equation (5) should read:

$$
\frac{\mathrm{d} P(D)}{\mathrm{d} D}=(\gamma-1) D^{-\gamma} /\left(D_{S^{1-\gamma}}-D_{L}{ }^{1-\gamma}\right)
$$

Erratum. In the review of the book Classification and Human Evolution, edited by Sherwood L. Washburn (Nature, December 5, p. 951), the heading of the chapter by G. A. Harrison and J. S. Weiner was unfortunately printed as "Some Considerations in the Formulation of Theories of Human Physiology"; for 'Physiology' read 'Phylogeny'. 